ORIGINAL ARTICLE

\title{
Hospital admission of high risk infants for respiratory syncytial virus infection: implications for palivizumab prophylaxis
}

\author{
T Heikkinen, H Valkonen, L Lehtonen, R Vainionpää, O Ruuskanen
}

Arch Dis Child Fetal Neonatal Ed 2005;90:F64-F68. doi: 10.1136/adc.2003.029710

See end of article for authors' affiliations

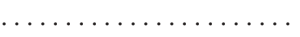

Correspondence to: Dr Heikkinen, Department of Paediatrics, Turku University Hospital, FIN-20520 Turku, Finland; terho.heikkinen@utu.fi

Accepted 7 October 2003

\begin{abstract}
Objectives: To determine the rates of hospital admission for respiratory syncytial virus (RSV) infection among children born at different gestational ages. To assess the theoretical impact of palivizumab prophylaxis on admissions for RSV infection.

Design: Retrospective cohort study of children born in 1991-2000.

Setting: Tertiary care university hospital.

Methods: Data on all children born during the 10 year period were combined with information on laboratory confirmed RSV infections in these children until the end of 2002. The theoretical impact of palivizumab on RSV associated admissions was estimated by applying the current recommendations for prophylaxis to the study population and using the observed rates of admission in the calculations.

Interventions: None.

Main outcome measures: Rates of RSV infection and hospital admission in different subgroups of children. Results: Children with chronic lung disease (CLD) were admitted for RSV infection at a rate of $12.0 \%$. The corresponding rates in children born at $\leqslant 28$ or $29-32$ weeks gestation were $7.1 \%$ and $6.8 \%$ respectively. Children born at $\leqslant 32$ weeks gestation accounted for $6.6 \%$ of all admissions due to RSV. Of 586 children who would have met the criteria for palivizumab prophylaxis, 27 (4.6\%) were admitted with RSV during the presumed prophylactic period. The number needed to treat to prevent one admission for RSV infection was 15 for children with CLD (with a total cost of $€ 75000$ ) and 43 for children without CLD born at $\leqslant 32$ weeks gestation (with a total cost of $€ 215000$ ).

Conclusions: The rates of hospital admission for RSV infection in premature infants were substantially lower than those in most previous reports from other countries. Determination of the local rates of RSV admissions in different groups of children would be useful in making decisions about the use of palivizumab.
\end{abstract}

In this population based study, we determined the rates of RSV admission in various subgroups of infants and children born at our hospital during 1991-2000. On the basis of these data, we estimated the theoretical impact of palivizumab prophylaxis on reducing RSV admissions among children with prematurity or CLD in our area.

\section{MATERIALS AND METHODS}

The study population consisted of all children born at Turku University Hospital during the 10 year period 1991-2000. Turku University Hospital is the only tertiary care hospital in Southwestern Finland and it serves a population of about 750000 . Virtually all risky deliveries occurring in the area, the medical care of premature infants, and the treatment of paediatric infections requiring admission are carried out at our hospital.

Data on all children born at our hospital during the study period were provided by the Department of Obstetrics. Together with detailed information on all premature infants treated at our neonatal intensive care unit, the children were classified into four groups according to their gestational age: $\leqslant 28$ weeks; 29-32 weeks; $33-35$ weeks; $\geqslant 36$ weeks. In addition, all children with CLD were placed into a separate fifth group regardless of gestational age. Children were considered to have CLD if they had still needed supplemental oxygen at the age corresponding to 36 weeks gestation or if

Abbreviations: CLD, chronic lung disease; RSV, respiratory syncytial virus is a major factor in any pharmacoeconomic analyses aimed at developing policies to reduce the impact of RSV in the society. 


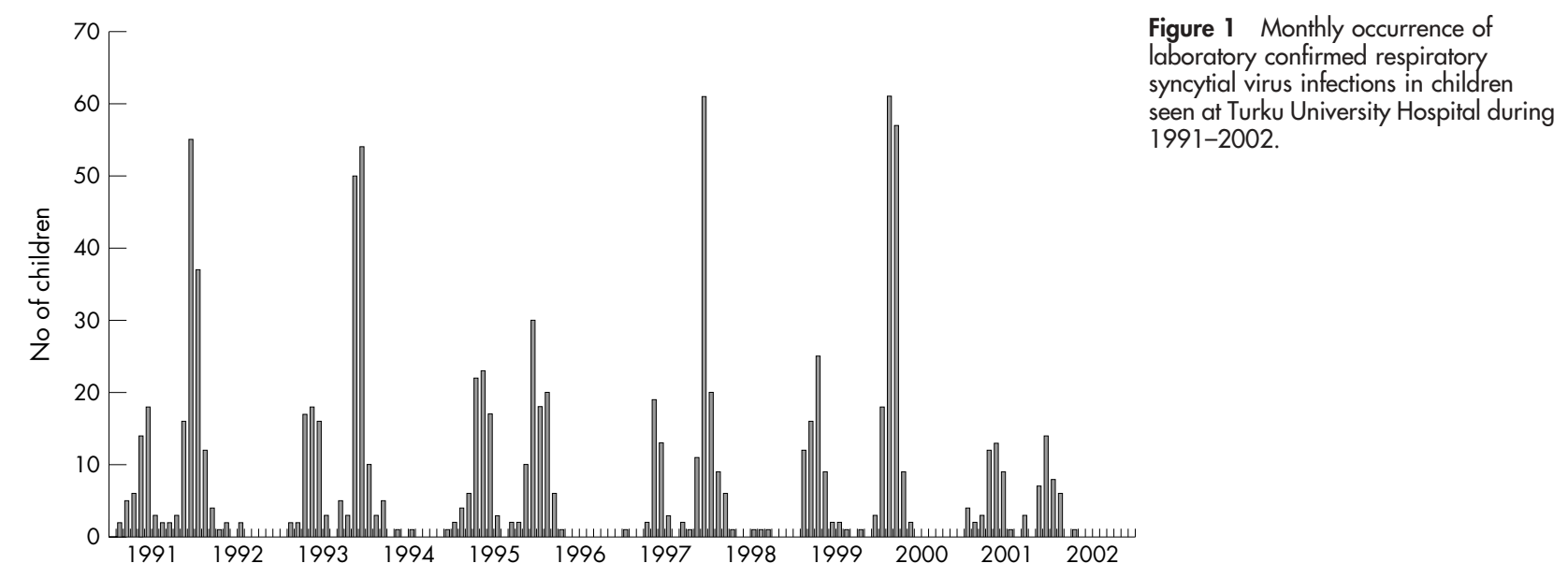

children younger than 2 years of age had required medical treatment for their lung disease within six months of the start of the RSV season. Four children with CLD had received palivizumab, and they were excluded from the analyses. Of a total of 25 children with CLD included in the study, 20 were born at $\leqslant 28$ weeks, four at $29-32$ weeks, and one at 3335 weeks gestation. The rationale for choosing these groups was to match the current recommendations for the use of palivizumab. ${ }^{8}$

To enable determination of the children's RSV morbidity up to at least 2 years of age, the virological follow up was continued until the end of December 2002. Information on all children with laboratory confirmed RSV infection seen at our hospital during 1991-2002 was provided by the Department of Virology, University of Turku. The determination of the viral aetiology of the infections was based on viral antigen detection in nasopharyngeal aspirates from the children. ${ }^{21}$ During the study period, a total of 7248 nasopharyngeal aspirates were obtained for viral detection from children at our hospital. The medical records of all children with confirmed RSV infection were carefully examined, and their clinical data were entered into a computerised database. In addition, to guarantee that we found all RSV infections in infants born prematurely, the medical records of all children born at $\leqslant 32$ weeks gestation without prior evidence of RSV infection were hand searched. This search yielded four cases of RSV infection that were not included in the original virological reports. Examination of the medical records also revealed that, during the entire 12 year follow up period, there were only four children born at $\leqslant 32$ weeks gestation who were admitted to hospital during an RSV epidemic for any type of respiratory infection without a nasopharyngeal aspirate being obtained. All these children were born at 2932 weeks gestation.

The definition of the start and the end of each RSV season was based on the numbers of children with laboratory confirmed RSV infection seen at our hospital (fig 1). In Finland, RSV epidemics follow a distinct two year pattern, with a small outbreak during the spring of every odd numbered year and a major outbreak during the subsequent autumn and winter. ${ }^{22}$ The spring RSV season was considered to have started on the day when the second child with confirmed RSV infection was seen at our hospital, and the autumn season was defined as having started on the day when the second child with RSV after the beginning of October was seen at the hospital. The spring and autumn epidemics were both considered to be over on the day after which no children with RSV were seen at the hospital during the subsequent two weeks.
For assessment of the theoretical impact of palivizumab prophylaxis on RSV admissions in our area, the prophylaxis was presumed to be started at the beginning of each RSV epidemic to all children born at $\leqslant 28$ weeks who on that day were younger than 1 year, to children born at 29-32 weeks who were younger than 6 months, and to those with CLD who were younger than 2 years. ${ }^{8}$ The prophylaxis was assumed to be discontinued at the end of the RSV epidemic or when the children reached their individual age limits for prophylaxis, whichever came first.

Proportions between various groups of children were compared by the standard $\chi^{2}$ test. $p \leqslant 0.05$ was considered to indicate significance.

\section{RESULTS}

\section{Children}

During the 10 year period of 1991-2000, a total of 35811 children were born alive at Turku University Hospital, and 1828 children born at $\leqslant 35$ weeks gestation survived the perinatal period. Twenty nine $(0.08 \%$ of all children born during the study period) children had CLD, 168 (0.5\%) were born at $\leqslant 28$ weeks gestation, and $498(1.4 \%)$ were born at 29-32 weeks gestation (table 1). Four children with CLD had received palivizumab prophylaxis, and they were excluded from further analyses. Altogether 691 (1.9\%) of the analysed children either had CLD or were born at a gestational age of $\leqslant 32$ weeks.

Table 1 Numbers of children born in 1991-2000 at $\leqslant 35$ weeks gestation who survived the perinatal period

\begin{tabular}{lllll}
\hline Year & CLD* & $\leqslant$ 28 weeks & 29-32 weeks & 33-35 weeks \\
\hline 1991 & 4 & 14 & 58 & 101 \\
1992 & 3 & 18 & 50 & 100 \\
1993 & 5 & 12 & 34 & 133 \\
1994 & 0 & 12 & 32 & 118 \\
1995 & 0 & 20 & 46 & 105 \\
1996 & 2 & 20 & 60 & 133 \\
1997 & 2 & 21 & 42 & 97 \\
1998 & 2 & 26 & 51 & 115 \\
1999 & 3 & 12 & 66 & 111 \\
2000 & 4 & 13 & 59 & 120 \\
Total & 25 & 168 & 498 & 1133 \\
\hline
\end{tabular}

*Four children with CLD who received palivizumab prophylaxis are excluded from the table. Of the 25 children analysed, 20 were born at $\leqslant 28$ weeks, four at 29-32 weeks, and one at 33-35 weeks gestation. CLD, Chronic lung disease. 
Table 2 Rates of respiratory syncytial virus (RSV) infection and admission to hospital in the study cohort

\begin{tabular}{lllll}
\hline & No & No with RSV & No admitted for RSV & \% admitted for RSV* \\
\hline CLD & 25 & 3 & 3 & 12.0 \\
$\leqslant 28$ weeks & 168 & 12 & 12 & 7.1 \\
$29-32$ weeks & 498 & 35 & 34 & 6.8 \\
$33-35$ weeks & 1133 & 50 & 42 & 3.7 \\
$\geqslant 36$ weeks & 33983 & 806 & 650 & 1.9 \\
Total & 35807 & 906 & 741 & 2.1 \\
\hline *Percentage of the total number of children in the group. \\
CLD, Chronic lung disease.
\end{tabular}

Table 3 Age of the children at the diagnosis of respiratory syncytial virus (RSV) infection

\begin{tabular}{|c|c|c|c|c|}
\hline & $<6$ months & 6-11 months & 12-23 months & $\geqslant 2$ years \\
\hline CLD & 1 & 0 & 2 & 0 \\
\hline$\leqslant 28$ weeks & 5 & 4 & 1 & 2 \\
\hline 29-32 weeks & 16 & 9 & 9 & 1 \\
\hline 33-35 weeks & 33 & 8 & 6 & 3 \\
\hline$\geqslant 36$ weeks & 433 & 156 & 131 & 86 \\
\hline Total & 488 & 177 & 149 & 92 \\
\hline
\end{tabular}

\section{Presumed palivizumab prophylaxis}

All 25 children with CLD met the recommended criteria for palivizumab prophylaxis. In the other groups, $166(98.8 \%)$ of 168 children born at $\leqslant 28$ weeks and 395 (79.3\%) of 498 children born at 29-32 weeks gestation met the criteria for prophylaxis. Of all children in the study cohort, 586 (1.6\%) would have met the criteria for palivizumab prophylaxis at some time during their lives.

\section{Admissions due to RSV}

A total of 906 children seen at the ambulatory clinic during the study period had a laboratory confirmed RSV infection, and $741(81.8 \%)$ of them were admitted to hospital (table 2 ). The percentages of all children with RSV who were admitted to hospital in the different groups were: CLD, 100\%; $\leqslant 28$ weeks, $100 \% ; 29-32$ weeks, $97 \%$; 33-35 weeks, $84 \%$; and $\geqslant 36$ weeks, $81 \%$. Of the 741 children admitted because of RSV infection, 49 (6.6\%) either had CLD or were born at $\leqslant 32$ weeks gestation. Fifty four percent of all children with RSV acquired the infection before the age of 6 months, and $73 \%$ by the age of 1 year (table 3 ). There were no apparent differences in the timing of RSV infection between the subgroups of children.

Table 2 shows the overall rates of RSV admission in different groups of children. Children with CLD were admitted to hospital at a significantly higher rate than children born at $\geqslant 36$ weeks gestation $(p=0.003)$. The differences in the admission rates between children with CLD and those born at $\leqslant 28,29-32$, or 33-35 weeks gestation were not significant. Compared with children born at $\geqslant 36$ weeks gestation, the relative risk of admission for RSV in children with CLD was 6.3 (95\% confidence interval (CI) 2.2 to 18.2). The corresponding relative risk for all children born at $\leqslant 32$ weeks gestation without CLD was 3.6 (95\% CI, 2.7 to 4.8), and that for children born at 33-35 weeks gestation was 1.9 (95\% CI 1.4 to 2.6 ).

Table 4 shows the numbers of children with CLD or a gestational age of $\leqslant 32$ weeks who were admitted to the intensive care unit. Overall, 14 (29\%) of the 49 children were treated at the intensive care unit, and four $(8 \%)$ of them were mechanically ventilated.

Theoretical effect of palivizumab on RSV admissions Children who met the criteria for palivizumab prophylaxis and who were admitted to hospital with RSV infection during the presumed prophylactic period represent the group of children whose hospital admissions could theoretically have been reduced with the use of palivizumab. Of the 586 children meeting the criteria for prophylaxis, 27 (4.6\%) were admitted with RSV infection within their individual periods of prophylaxis (table 5). The rate of admission during the presumed prophylaxis in children with CLD (12.0\%) tended to be higher than the average rate in children without CLD born at $\leqslant 32$ weeks gestation $(4.3 \%)$, but the difference was not significant (relative risk 2.8; $95 \%$ CI 0.9 to 8.7 ).

Assuming that the use of palivizumab would have decreased the rates of admission by $55 \%$ in each group, the number of children needed to treat to prevent one admission of a child with CLD was 15 . In children born at $\leqslant 28$ weeks or 29-32 weeks gestation, the corresponding numbers needed to treat were 38 and 45 respectively (the number needed to treat for these two groups combined was 43).

Twenty two children with a gestational age of $\leqslant 32$ weeks (four born at $\leqslant 28$ weeks and 18 at 29-32 weeks) were admitted to hospital with RSV infection after the presumed prophylactic period, or they did not meet the criteria for prophylaxis at any time. These 22 children constituted $45 \%$ of all 49 RSV admissions in children who either had CLD or were born at $\leqslant 32$ weeks gestation.

Table 4 Numbers of children treated in the intensive care unit for respiratory syncytial virus (RSV) infection

\begin{tabular}{llll}
\hline & $\begin{array}{l}\text { No admitted to } \\
\text { hospital with RSV }\end{array}$ & $\begin{array}{l}\text { No treated in } \\
\text { intensive care unit }\end{array}$ & $\begin{array}{l}\text { No requiring } \\
\text { mechanical ventilation }\end{array}$ \\
\hline CLD & 3 & $2(67)$ & $0(0)$ \\
$\leqslant 28$ weeks & 12 & $3(25)$ & $2(17)$ \\
$29-32$ weeks & 34 & $9(26)$ & $2(6)$ \\
Total & 49 & $14(29)$ & $4(8)$ \\
\hline Values in parentheses are percentages. \\
CLD, Chronic lung disease.
\end{tabular}


Table 5 Rates of admission for respiratory syncytial virus (RSV) infection in children during their presumed periods of palivizumab prophylaxis

\begin{tabular}{llll}
\hline & $\begin{array}{l}\text { No of children meeting } \\
\text { criteria for prophylaxis }\end{array}$ & $\begin{array}{l}\text { No admitted with RSV } \\
\text { during prophylaxis }\end{array}$ & $\begin{array}{l}\text { \% admitted with RSV } \\
\text { during prophylaxis }\end{array}$ \\
\hline CLD & 25 & 3 & 12.0 \\
$\leqslant 28$ weeks & 166 & 8 & 4.8 \\
$29-32$ weeks & 395 & 16 & 4.1 \\
Total & 586 & 27 & 4.6 \\
\hline CLD, Chronic lung disease. & & \\
\hline
\end{tabular}

\section{DISCUSSION}

The results of our extensive follow up study show that only $5 \%$ of all children born at $\leqslant 35$ weeks and $7 \%$ of those born at $\leqslant 32$ weeks gestation were admitted to hospital for RSV infection. In previous studies of RSV admissions among premature infants, the rates have varied between 3\% and $24 \% .^{79-14}{ }^{18-20}$ It should be noted, however, that comparing rates observed in various studies is extremely problematic because of great differences in methodology and the demographics of the study populations. This is especially true with respect to the proportions of children with CLD in whom the admission rates have been consistently much higher than in premature infants without CLD. However, even when focusing on comparable groups of children-for example, infants born at $\leqslant 35$ weeks gestation without CLD—our admission rate $(4.9 \%)$ was substantially lower than that observed in the major efficacy trial of palivizumab $(8.1 \%) .{ }^{7}$ The reasons for this difference remain unknown, but potential explanations could include the good general health of preterm infants in Finland and the parental education and general awareness about RSV disease in our country, which may have resulted in decreased exposure to RSV of premature infants.

Although the efficacy of palivizumab in reducing RSV related admissions among premature infants is unquestionable, $^{7}$ the results of efficacy trials in carefully selected populations are not directly applicable to everyday clinical practice, and the real life effectiveness of palivizumab prophylaxis may be much lower. However, even though the effectiveness of palivizumab equalled the efficacy figures observed in pivotal clinical trials, the key issue from the perspective of public health is not the relative reduction but the attributable risk reduction in RSV related admissions. The attributable risk reduction is derived by subtracting the rate of admission among palivizumab recipients from the corresponding rate in children without the prophylaxis, and it reflects the real impact of the intervention at the level of society. The baseline incidence of RSV admission in children without palivizumab is a major factor affecting the magnitude of the attributable risk reduction, and therefore it is also one of the main driving factors in any cost effectiveness calculations.

On the basis of our results and assuming a 55\% prophylactic efficacy of palivizumab, 43 children born at $\leqslant 32$ weeks gestation without CLD would need to be treated with palivizumab to prevent one RSV related admission. With an average of five doses of palivizumab per child ${ }^{23}$ at a cost of $€ 1000$ per dose, the total cost of preventing one admission among these children would be about $€ 215000$. In children with CLD, in whom the number needed to treat was 15 , the cost to prevent one admission would be about $€ 75000$.

Determination of the incidence of RSV related admissions depends on the frequency of obtaining specimens for viral identification, and obviously a low sampling frequency may substantially underestimate the rate of RSV admission. ${ }^{10}$ During the years of this study, nasopharyngeal aspirates were routinely obtained from virtually all children admitted to our hospital for bronchiolitis or other respiratory illnesses, and therefore it is unlikely that underdetection of RSV would have substantially affected the observed rates of admission in different groups of children. The extent of our sampling for viral detection was further confirmed during the hand search of the medical records which revealed that, during the study period, a nasopharyngeal aspirate was obtained from all but four children born at $\leqslant 32$ weeks gestation who were admitted to hospital for respiratory symptoms during an RSV epidemic.

Considering the high cost of palivizumab prophylaxis, the use of this intervention appears to be justified only in carefully selected groups of children in our area. With the current price of the product, the prophylaxis can hardly be cost saving in any children, and the extent to which palivizumab will be used depends largely on how much society is willing to pay for reduced admission or decreased potential for long term risks in certain groups of premature children. ${ }^{24}$ Our results underscore the importance of determining the local rates of RSV admission among different groups of children and using such locally derived estimates in making decisions about the use of palivizumab prophylaxis.

\section{ACKNOWLEDGEMENTS}

We thank Anne Riihimäki, RN, for her excellent assistance in the conduct of the study. The study was supported by the Academy of Finland and Abbott Laboratories (Finland).

\section{Authors' affiliations}

T Heikkinen, H Valkonen, L Lehtonen, R Vainionpää, O Ruuskanen, Department of Paediatrics, Turku University Hospital, Turku, Finland

Competing interests: none declared

\section{REFERENCES}

1 Ruuskanen O, Ogra PL. Respiratory syncytial virus. Curr Probl Pediatr 1993;23:S50-79.

2 Groothuis JR, Gutierrez KM, Lauer BA. Respiratory syncytial virus infection in children with bronchopulmonary dysplasia. Pediatrics 1988;82:199-203.

3 Cunningham CK, McMillan JA, Gross SJ. Rehospitalization for respiratory illness in infants of less than 32 weeks' gestation. Pediatrics 1991;88:527-32.

4 Englund JA. Prevention strategies for respiratory syncytial virus: passive and active immunization. J Pediatr 1999;135:S38-44.

5 Simoes EAF. Respiratory syncytial virus infection. Lancet 1999;354:847-52.

6 Johnson S, Oliver C, Prince GA, et al. Development of a humanized monoclonal antibody (MEDI-493) with potent in vitro and in vivo activity against respiratory syncytial virus. J Infect Dis 1997;176:1215-24.

7 The IMpact-RSV Study Group. Palivizumab, a humanized respiratory syncytial virus monoclonal antibody, reduces hospitalization from respiratory syncytial virus infection in high-risk infants. Pediatrics 1998; 102:531-7.

8 American Academy of Pediatrics. Prevention of respiratory syncytial virus infections: indications for the use of palivizumab and update on the use of RSV-IGIV. Pediatrics 1998;102:1211-16.

9 Joffe S, Escobar GJ, Black SB, et al. Rehospitalization for respiratory syncytial virus among premature infants. Pediatrics 1999;104:894-9.

10 Clark SJ, Beresford MW, Subhedar NV, et al. Respiratory syncytial virus infection in high risk infants and the potential impact of prophylaxis in a United Kingdom cohort. Arch Dis Child 2000;83:313-16.

11 Thomas M, Bedford-Russell A, Sharland M. Hospitalisation for RSV infection in ex-preterm infants: implications for use of RSV immune globulin. Arch Dis Child 2000;83:122-7. 
12 Boyce TG, Mellen BG, Mitchel EF, et al. Rates of hospitalization for respiratory syncytial virus infection among children in Medicaid. J Pediatr 2000;137:865-70.

13 Stevens TP, Sinkin RA, Hall CB, et al. Respiratory syncytial virus and premature infants born at 32 weeks' gestation or earlier. Arch Pediatr Adolesc Med 2000; 154:55-61

14 Fariña D, Rodriguez SP, Bauer G, et al. Respiratory syncytial virus prophylaxis: cost-effective analysis in Argentina. Pediatr Infect Dis J 2002;21:287-91.

15 Moler FW, Brown RW, Faix RG, et al. Comments on palivizumab (Synagis) Pediatrics 1999:103:495-7.

16 Sharland $M$, Bedford-Russell A. Preventing respiratory syncytial virus bronchiolitis. BMJ 2001;322:62-3.

17 Kamal-Bahl S, Doshi DJ, Campbell J. Economic analyses of respiratory syncytial virus immunoprophylaxis in high-risk infants: a systematic review. Arch Pediatr Adolesc Med 2002;156:1034-41.

18 McCormick J, Tubman R. Readmission with respiratory syncytial virus (RSV) infection among graduates from a neonatal intensive care unit. Pediatr Pulmonol 2002;34:262-6.
19 Shireman TI, Braman KS. Impact and cost-effectiveness of respiratory syncytial virus prophylaxis for Kansas Medicaid's high-risk children. Arch Pediatr Adolesc Med 2002;156:1251-5

20 Carbonell-Estrany X, Quero J, IRIS Study Group. Hospitalization rates for respiratory syncytial virus infection in premature infants born during two consecutive seasons. Pediatr Infect Dis J 2001;20:874-9.

21 Waris M, Meurman O, Mufson MA, et al. Shedding of infectious virus and virus antigen during acute infection with respiratory syncytial virus. J Med Virol 1992;38:111-16.

22 Waris M. Pattern of respiratory syncytial virus epidemics in Finland: two-year cycles with alternating prevalence of groups $A$ and $B$. J Infect Dis 1991; 163:464-9.

23 Oh PI, Lanctot KL, Yoon A, et al. Palivizumab prophylaxis for respiratory syncytial virus in Canada: utilization and outcomes. Pediatr Infect Dis J 2002;21:512-18.

24 Greenough A, Cox S, Alexander J, et al. Health care utilisation of infants with chronic lung disease, related to hospitalisation for RSV infection. Arch Dis Child 2001;85:463-8.

\section{Call for papers}

10th European Forum on Quality Improvement in Health Care

13-15 April 2005, ExCel, Docklands, London

For further information on how to submit your paper please go to:

http://www.quality.bmipg.com 